\title{
As políticas de valorização docente Uma realidade dos professores do campo
}

Adriana Ramos dos Santos*

RESUMO: O trabalho se propõe a analisar as políticas de valorização dos docentes do campo no estado do Acre, a fim de evidenciar se estão produzindo condições de valorização para reduzir os efeitos da desigualdade, e propiciando condições de mais equidade no cenário educacional, já que o aumento na titulação vem sendo planejado e executado de forma isolada e desarticulada.

Palavras-Chave: Políticas educacionais. Professores do campo. Valorização docente.

\section{Introdução}

valorização dos profissionais da educação é um tema cada vez mais presente nos debates educacionais. Há certo consenso de que os profissionais 11 sofrem um processo de desvalorização há décadas no Brasil. Dentre as políticas que na atualidade buscam responder às demandas por maior valorização docente, destacam-se as de formação, que têm adquirido relevância devido à necessidade de responder às exigências de titulação ao conjunto dos professores que atuam nas escolas de educação básica.

Este artigo se propõe a analisar as políticas voltadas à valorização dos docentes do campo no estado do Acre, na tentativa de evidenciar se tais políticas estão produzindo ou não condições de valorização, contribuindo para reduzir os efeitos das desigualdades e propiciando condições de mais equidade no cenário educacional.

* Doutora em Educação. Professora efetiva (DE) na Universidade Federal do Acre (UFAC), Campus Rio Branco, no Centro de Educação, Letras e Artes (Cela) nas áreas de Didática Aplicada ao Ensino de Ciências e Biologia, Ensino de Ciências e Estagio Supervisionado. Rio Branco/AC-Brasil. E-mail:<adrianaramos.ufac@gmail.com>. 
Em âmbito nacional existem documentos e leis que compõem a política de valorização do professor nos dias atuais. Faz-se importante, antes de apresentar os contextos legais, destacar seu conceito, pois, para compreender a valorização do professor também é preciso refletir sobre o seu próprio sentido. A definição utilizada aqui é a construída por Grochoska, que afirma ser a valorização

\footnotetext{
Um princípio constitucional que se efetiva por meio de um mecanismo legal chamado carreira, que se desenvolve por meio de três elementos, sendo: a) formação, b) condições de trabalho e c) remuneração, tendo como objetivos a qualidade da educação e a qualidade de vida do trabalhador $(2015$, p.28).
}

Para Grochoska (2015) a carreira é o mecanismo legalmente instituído na forma da lei que define normas e regras que propiciam o desenvolver da vida funcional do professor - podendo ou não promover sua valorização - e que a construção do conceito de valorização deve estar intrinsecamente ligada a duas concepções: a primeira, a qualidade de ensino; a segunda, a qualidade de vida e bem-estar do trabalhador, tendo como mecanismo a carreira, que se desenvolve por meio de três elementos que viabilizam esta valorização, a formação; as condições de trabalho e a remuneração.

Os elementos inclusos nesse conceito são frutos dos debates nacionais, das pautas da categoria, e também se apresentam nas leis nacionais que tratam da valorização. A pesquisa utilizou dados quantitativos e qualitativos coletados por meio de Censo Escolar do Inep (2013) e da análise documental que passa pela LDB nº 9.394, de 1996, o Plano Nacional de Educação, a Lei do Piso Salarial Profissional Nacional dos professores (Lei nº 11.738, de 2008), a Resolução nº 2, de 2009, que fixa as Diretrizes Nacionais para os Planos de Carreira e Remuneração dos Profissionais do Magistério da Educação Básica Pública e as legislações estaduais que regulamentam a carreira dos professores no Acre. Por meio dessa legislação, buscam-se elementos que apontem de que forma vem se configurando a carreira do professor em exercício hoje, especialmente daqueles que atuam no campo, a fim de se identificar os avanços, recuos e permanências legais incorporados à política de valorização docente no país.

\section{A valorização docente na legislação nacional}

As políticas de valorização docente tomam por base algumas leis nacionais que regulamentam e embasam a educação, dentre elas destacam-se a LDB no 9.394, de 1996, apresentando elementos de grande importância para a execução de uma política de valorização do magistério, sinalizando que os sistemas de ensino promoverão a valorização dos profissionais da educação, assegurando-lhes, inclusive, nos termos dos estatutos e dos planos de carreira do magistério público, 
ingresso exclusivamente por concursos de provas e títulos; aperfeiçoamento profissional continuado, inclusive com licenciamento periódico remunerado para tal fim; piso salarial profissional; progressão funcional baseada na titulação ou habilitação, e na avaliação de desempenho; período reservado a estudos, planejamento e avaliação, incluindo na carga de trabalho; condições adequadas de trabalho (BRASIL, 1996).

Além disso, a Lei incentiva a formação em nível superior e, para tanto, define as premissas referentes à formação, às exigências de habilitação e às condições que assegurem a valorização dos professores.

No Plano Nacional de Educação para o decênio 2014-2024, o tema da valorização e formação dos profissionais da educação encontra-se mais fortemente destacado entre as metas 15 e 18. Na meta 15 são especificadas estratégias voltadas para a formação de professores, inclusive dos que atuam no campo:

15. 5) implementar programas específicos para formação de profissionais da educação para as escolas do campo e de comunidades indígenas e quilombolas e para a educação especial;

\section{$[\cdots]$}

15. 9) Implementar cursos e programas especiais para assegurar formação específica em sua área de atuação aos docentes com formação de nível médio na modalidade normal, não licenciados ou licenciados em área diversa da de atuação docente, em efetivo exercício.

A meta 17 pretende equiparar o rendimento médio dos professores ao dos demais profissionais com escolaridade equivalente, até o final do sexto ano de vigência deste PNE. Já a meta 18 fixa o prazo de dois anos para a implantação de planos de carreira para os profissionais da educação básica e superior pública de todos os sistemas de ensino e para o plano de carreira dos profissionais da educação básica pública, tomando como referência o piso salarial nacional profissional.

No Plano Estadual de Educação do estado do Acre (PEE), observa-se que também existe certa preocupação com a valorização docente, especialmente no tocante a formação:

11.20. Assegurar e fomentar, até o final do quinto ano de vigência deste plano, que todos os profissionais docentes, com atuação nas escolas rurais, tenham a formação inicial exigida para o exercício do magistério;

11.21. Desenvolver programa de formação continuada para os profissionais docentes lotados nas áreas rurais que contemple o universo rural, os direitos, objetivos e expectativas de aprendizagem definidos na base nacional comum e as estratégias metodológicas adequadas a cada etapa da escolarização. (PEE-ACRE, 2015) 
O PEE, assim como o PNE, destaca a importância da formação inicial e continuada do professor do campo, mas apesar dos avanços da legislação, referentes à valorização da carreira docente, muitas dessas medidas não chegaram a se consubstanciar em melhorias salariais significativas e em planos de carreira.

Outro aspecto imprescindível é a discussão das condições de trabalho dos professores, implementando ações para que permaneçam nas escolas do campo, pois pouco se fala a respeito da necessidade da melhoria nas condições de trabalho, que vão desde o salário, a jornada de trabalho, a autonomia profissional, o número de alunos por sala de aula, até a situação física dos prédios escolares onde trabalham.

A Resolução nº 2, de 2009 fixa as Diretrizes Nacionais para os Planos de Carreira e Remuneração dos Profissionais do Magistério da Educação Básica Pública, se consolidou como um importante referencial para a valorização do professor, pois reafirma elementos importantes para a consolidação desta política, como ingresso, formação, jornada, 20\% de hora-atividade, progressões e remuneração (BRASIL, 1997). Em seu artigo $4^{\circ}$, a Resolução prescreve que todos os entes federados devem instituir planos de carreira para os profissionais da educação que atuem nas escolas e órgãos da rede de educação básica, incluindo todas as suas modalidades. Além disso, define que os planos de carreira podem estabelecer a jornada semanal de trabalho dos docentes em até 40 horas, incluindo uma parte de horas de aula e outra de horas de atividades ${ }^{1}$, estas últimas correspondendo a um percentual entre $20 \%$ (vinte por cento) e $25 \%$ (vinte e cinco por cento) do total da jornada.

Sobre a remuneração, define que os profissionais do magistério devem ter vencimentos ou salários iniciais nunca inferiores aos valores correspondentes ao Piso Salarial Profissional Nacional, que devem ser fixados de acordo com a jornada de trabalho, definida nos respectivos planos de carreira, diferenciados pelos níveis das habilitações, vedada qualquer diferenciação em virtude da etapa ou modalidade de atuação do profissional.

Outras iniciativas foram instituídas com a finalidade de valorizar os docentes, ainda que em patamares incipientes, tais como a Lei no 11.738 , de 1998, que instituiu o Piso Salarial Profissional Nacional (PSPN) para os profissionais do magistério público da educação básica. No artigo $2^{\circ}$, estabeleceu que o $\mathrm{PSPN}^{2}$ seria de $\mathrm{R} \$ 950,00$ mensais, para a formação em nível médio, na modalidade normal. Acrescentou, no parágrafo primeiro, que a União, os estados, o Distrito Federal e os municípios não poderiam fixar o vencimento inicial das carreiras do magistério público, na educação básica, para jornada de, no máximo, 40 horas semanais, abaixo do valor estipulado pela Lei.

A partir de 2009, esse valor deveria ser reajustado anualmente, sempre no mês de janeiro (art. $5^{\circ}$ ). Tendo em vista o cumprimento do piso salarial profissional nacional para os profissionais do magistério público da educação básica, a União, os estados, o Distrito Federal e os municípios deveriam elaborar ou adequar seus planos de carreira 
e remuneração do magistério até 31 de dezembro de 2009 (art. 6º $)$. Segundo a Lei, os estados e municípios teriam até $1^{\circ}$ de janeiro de 2010 para começar a pagar o piso que, em valores atualizados, corresponderia a $\mathrm{R} \$ 1.024$, segundo correção feita pelo MEC na data em que o piso se tornou obrigatório em todo o País. O valor do piso é atualizado anualmente. Em 2011, o valor foi de R \$1.187,97 para docentes de nível médio que cumprem carga horária de 40 horas semanais. Isso representou uma alta de $15,84 \%$ sobre os R\$ 1.024,67 adotados em 2010. Em janeiro de 2015, o piso salarial do magistério foi reajustado em 13,01\%, passando para R $\$ 1.917,78$.

A ideia de valorização do magistério, por meio de planos de carreira, ainda encontra-se em um cenário muito desigual, pois, na diversidade de contextos locais brasileiros, encontram-se situações de ausência de planos, de planos aprovados, porém não efetivados, e uma gama imensa de planos de carreira com lógicas distintas, em execução. As regulamentações legais demonstram, em alguma medida, a valorização profissional, ou seja, revelam o reconhecimento pelo trabalho desenvolvido pelo professor. Apesar de determinar algumas medidas que o valorizem, independente de seu contexto de atuação, não fazem proposições quanto às formas de efetivá-la, não explicitam quais os meios para que os objetivos determinados no texto legal sejam concretizados. Isso fragiliza a execução da política, e abre a possibilidade de que, ao serem implementadas, contraditoriamente, se voltem contra as mesmas reinvindicações históricas, especialmente no campo, onde a desigualdade de condições de trabalho é maior e mais adversa.

As políticas educacionais desenhadas nas últimas décadas trataram, fundamentalmente, de criar o arcabouço legal - normatizações e regulações - para a valorização profissional dos quadros do magistério da educação básica. A legislação proclama a profissionalização, por meio da definição de critérios para o exercício das funções docentes, a possibilidade de organização e reconhecimento de uma carreira profissional, a exigência de cursos de formação docente, dentre outras. Destacam-se a relevância e o valor social da determinação legal para a defesa das históricas reivindicações dos profissionais da educação, especialmente os do campo. Todavia, a maioria das conquistas ainda não conseguiu alterar as condições de trabalho, garantir planos de carreira e piso salarial efetivamente mais atraente para a profissão.

\section{As políticas de formação para os docentes no Acre}

O estado do Acre passou a implementar, a partir de 2000, um plano de reformas que tinha como objetivo investir na qualificação dos docentes da rede pública de ensino. Para tanto, a gestão da Secretaria de Estado (SEE/AC) elaborou e executou um Plano Estratégico que priorizava a formação dos professores, especialmente em serviço, com 
uma série de programas especiais. Os programas eram voltados tanto para a formação dos professores leigos, quanto para a formação inicial e continuada.

Inicialmente, foi implantado o Programa de Formação de Professores em Exercício (Proformação), desenvolvido pelo Ministério da Educação, que oferecia um curso de magistério, em nível de ensino médio, aos professores leigos. No Acre, 1.634 professores fizeram essa formação. Com a implementação desse programa, o estado se aproximou da formação mínima exigida na LDB, amenizando a questão da formação dos professores leigos. Entretanto, ainda enfrentava outro problema: a ausência de professores com nível superior para atuar na educação básica da rede pública de ensino. Diante desse fato, o governo passou a firmar convênio com a Universidade Federal do Acre (Ufac), implementando mais de dez programas de formação inicial em serviço para os professores da educação básica ${ }^{3}$.

Em consonância com a política nacional, a Ufac passou a elaborar e oferecer cursos de licenciatura para o estado do Acre. Cabe destacar que esta é a única instituição de ensino superior pública consolidada na formação de professores. Isso tem imposto desafios e demandas cada vez maiores na ampliação e oferta de vagas e à formação de profissionais qualificados para fazer frente às necessidades do desenvolvimento econômico, social, cultural e educacional da região.

As políticas de formação desenvolvidas no estado diferenciaram-se da maioria dos programas de formação adotados por vários estados brasileiros, pela modalidade em que foram ofertados os cursos superiores. Enquanto na maioria dos estados a formação em serviço se deu na modalidade à distância, no Acre, os primeiros programas de formação de professores foram desenvolvidos na forma presencial, em semestres regulares e dentro do próprio calendário acadêmico da instituição formadora. Nos últimos anos, a política de formação de professores em nível superior foi adotando modelos presenciais e à distância, ampliando-se, também, as parcerias com outras instituições universitárias (DAMASCENO, 2010).

Com a implementação dos programas de formação, a falta de professores com nível superior nas cidades foi amenizada, contudo, o campo ainda necessitava de formação para seus docentes. Devido à grande demanda, o estado foi desafiado a pensar, também, na formação desses professores. Para tanto, implementou o Programa de Formação de Professores da Educação Básica da Zona Rural (Profir/2007), que atendeu, aproximadamente 2.389 professores.

Inclui-se, no rol dos programas de formação para os professores do campo, o Plano Nacional de Formação de Professores da Educação Básica (Parfor), que, atualmente encontra-se em andamento no estado. Este programa não se destina, exclusivamente, à formação dos professores do campo. Contudo, merece destaque, tendo em vista que a maioria dos discentes matriculados nos cursos ofertados pelo programa são professores que atuam nessa localidade. Com a oferta iniciada em 2013 e em 2014, estão sendo 
ofertadas pelo Parfor, no Acre, 33 turmas de licenciatura, que perfazem uma matrícula aproximada de 1.500 (mil e quinhentos) professores da rede pública de ensino em processo de formação na educação superior.

É imprescindível destacar que as políticas de formação de professores no estado do Acre vêm configurando um novo perfil de professor, tanto do campo, quanto da cidade. O número de professores atendidos pelos programas é bastante expressivo e, em alguns aspectos, as ações mostram-se superiores, proporcionalmente, aos programas implementados em outros estados mais ricos, com infraestrutura melhor e mais adequada e condições geográficas mais favoráveis. Há, no entanto, outros desafios a serem enfrentados, que dizem respeito à valorização e às condições do trabalho docente.

\section{Formação, carreira e remuneração dos docentes do campo}

O Programa de Formação de Professores da Educação Básica da Zona Rural (Profir) qualificou, com ensino superior, um considerável número de professores no campo. Antes da implementação desse programa, apenas 26,0\% dos docentes possuíam nível superior e, ao seu término, em 2012, os dados indicam um crescimento significativo para $63,5 \%$. Além dos ganhos pessoais, pois ter a formação superior contribuiu para elevar a autoestima dos docentes, conferindo-lhes maior segurança profissional, observam-se mudanças substanciais correlacionadas com a formação, como por exemplo, a elevação na remuneração. Isso permitiu a muitos docentes melhor condição financeira para viver no campo. Em 2013, registrou-se um crescimento substancial para 65,2\%, mas ainda muito distante da realidade dos professores das escolas das cidades (92,3\%). Esses números permitem reafirmar que existe desigualdade no campo e que se expressa, sobretudo, pela comparação dos indicadores de formação superior dos professores da cidade.

É oportuno registrar que o Profir, apesar de ter contribuído para elevar o percentual de professores do campo com ensino superior, não foi capaz, sozinho, de reduzir o número de professores leigos, pois o Acre ainda vem contratando professores com esse perfil de formação, em caráter temporário. $\mathrm{O}$ crescimento dessa situação pode ser explicado por dois fatores que ocorrem simultaneamente: grande parte dos docentes, após a qualificação em nível superior, transferiu-se para a cidade, em busca de melhores condições de vida e de trabalho e a Secretaria de Educação, na busca por preencher essa vaga, esbarra na dificuldade de contratar docentes com a mesma formação que se disponham a atuar nesse contexto, dadas as dificuldades, tanto geográficas, quanto econômicas, do campo.

A política de carreira e remuneração dos professores da rede estadual do Acre é concretizada pelo Plano de Cargos, Carreira e Remuneração dos Profissionais do Ensino Público Estadual (PCCR), que foi instituído pela Lei Completar nº 67, de 1999. 
Atualmente, o PCCR, após sofrer várias alterações por Leis Complementares, compõe-se de dez classes para o professor com formação em licenciatura plena e nove para os professores com formação de nível médio (Curso Normal), com jornada contratual de trinta horas e promoção a cada três anos. Das trinta horas semanais, dois terços da carga horária são destinadas às atividades de interação direta do professor com o aluno, em sala de aula, e um terço para atividades distintas da sala de aula.

O PCCR estabelece dois níveis para a carreira do professor: P1 e P2. O professor P1 é o professor com formação de nível médio em magistério. O Professor P2 é o que possui formação em licenciatura plena. Existem outras classes que estão em processo de extinção pelo PCCR: Professor PE3, com formação em licenciatura curta; Professor PS1, com ensino fundamental completo; Professor PS2, com ensino médio completo, sem formação de magistério; e Professor PS3, com curso superior completo, sem formação em licenciatura.

A remuneração dos professores da educação básica da rede estadual acreana é decorrente do nível de escolaridade, do tempo de carreira, acrescida de algumas vantagens pecuniárias, tais como gratificações pelo exercício em escola de difícil acesso; pelo exercício de docência com alunos com necessidades educacionais especiais; por adicionais em cursos de pós-graduação na área da educação (especialização, mestrado e doutorado); por dedicação exclusiva; e outros.

Os professores com formação de nível médio em magistério (Professor P1) ingressavam na carreira com salário inicial de $\mathrm{R} \$ 1.175,79$, para uma jornada de 30 horas semanais. Para o ano de 2015, foi aprovada uma tabela salarial na qual o vencimento-base dos professores com essa formação passa a ser de $\mathrm{R} \$ 1.439,32$, para uma jornada de trabalho semanal de 30 horas. A tabela salarial apresentada pelo governo estadual indica, segundo a CNTE, o cumprimento dos valores fixados pela Lei do Piso, em 2013. O valor do vencimento inicial do piso era de $\mathrm{R} \$ 1.567,00$ para os que possuem normal médio, com uma jornada de 40 horas de trabalho semanais, destinando o limite máximo de dois terços da carga horária para o desempenho de atividades de interação com os educandos, devendo um terço ser dedicado à atividades extraclasse.

Os professores com formação superior ingressam na carreira do magistério acreano com salário inicial de $\mathrm{R} \$ 2.010,95$, para uma jornada de trinta horas de trabalho semanal, independentemente da etapa da educação básica em que atuam. Isso significa que o professor da educação infantil ou anos iniciais do ensino fundamental, ao ingressar na carreira, terá o mesmo vencimento que os professores das demais etapas. Já os docentes com nível superior, mas que não possuem licenciatura, recebem uma remuneração inicial de $\mathrm{R} \$ 1.137,60$.

Os professores que têm formação no ensino fundamental recebem um salário inicial de R \$678,72 e, para os formados no ensino médio, sem habilitação para o magistério, um salário de R \$754,00. Esses professores, concentrados, em sua maioria, no campo, 
encontram-se em fim de carreira no quadro da rede estadual de ensino, de acordo com o PCCR. A manutenção desses professores no mercado de trabalho acaba por demarcar a desvalorização do profissional da educação do campo, em termos de formação e de situação funcional. Isso porque, sob contratação temporária, ganham salários abaixo do mínimo nacional e também do mínimo do PSPN. O estado adota condições de trabalho diferentes para os professores temporários. No PCCR, a política de remuneração e a jornada de trabalho são explicitamente diferentes para os professores temporários e os efetivos, produzindo, assim, relações contratuais desiguais entre os profissionais.

Os professores contratados em regime temporário, com licenciatura plena, recebiam o correspondente a 75\% do valor recebido pelo professor efetivo, nas mesmas condições, estabelecido pelo Plano de Cargos, Carreira e Salários (Lei Completar nº 67, de 1999). Contudo, a partir do projeto de Lei Complementar nº 20, de 2013,

$\S 1^{\circ} \mathrm{O}$ vencimento dos professores temporários com licenciatura plena, em regime de vinte e cinco horas semanais, corresponderá a noventa por cento do valor recebido pelo professor efetivo, nível superior, em regime de trinta horas semanais, na classe e referência iniciais.

Todavia, apesar da elevação do percentual, esse professor continua em desvantagem, se comparado aos professores efetivos, pois recebe vencimentos inferiores e desiguais, sendo que realiza o mesmo trabalho. $\mathrm{O}$ vencimento dos professores com contrato temporário, com formação de nível médio em magistério, corresponde a cem por cento do valor recebido pelo professor P1 efetivo, na classe A. Todavia, ficam impossibilitados de progredir na carreira por tempo de serviço, pois sua situação de contratação temporária impede que acumulem os anos de serviços prestados à rede pública de ensino, sendo remunerados, sempre, com o vencimento da classe de acesso do plano de carreira.

No que se refere à jornada de trabalho, os professores com licenciatura plena terão, de acordo com o PCCR:

I - jornada de trinta horas semanais para os professores - nível I e II, do quadro suplementar, sendo dois terços da carga horária destinada às atividades de interação direta do professor com o aluno em sala de aula e um terço para atividades distintas da sala de aula.

$\S 7^{\circ} \mathrm{O}$ professor com contrato por tempo determinado terá jornada de trabalho de 25 horas semanais, sendo 20 horas em sala de aula e 5 horas de atividades, com remuneração baseada na classe de acesso, levando-se em conta a proporcionalidade da sua jornada de trabalho.

Observa-se, aqui, que os professores possuem a mesma carga horária em sala de aula que os professores efetivos (20h). No entanto, possuem apenas cinco horas-atividade, enquanto os efetivos possuem dez horas. A hora-atividade dos profissionais da educação é um importante indicador de qualidade na carreira docente. 
O número de docentes com contrato temporário vem evoluindo assustadoramente, em ambos os contextos. Contudo, a situação dos professores do campo é bem pior. Em 2013, o campo totalizava 85,1\% de professores com contrato temporário, na cidade esse percentual era de 51,8\%. A contratação de professores temporários transformou-se em política de estado no Acre, pois a contratação que deveria ser feita somente em regime especial tornou-se uma situação constante no quadro do magistério público acreano.

A falta de um vínculo profissional estável traz grandes prejuízos para as condições de vida pessoal e profissional dos docentes do campo. Isso porque o fato de não pertencerem ao quadro efetivo, não possuirem uma estabilidade trabalhista, muito menos progressão na carreira, acaba provocando mais insegurança para a realização do seu trabalho. Esses profissionais estão sujeitos a demissões a cada final do ano letivo, e estão submetidos a grande rotatividade, ao mudarem constantemente de escolas ou de comunidade, em função da instabilidade no emprego.

Os dados deixam evidente que a condição de remuneração dos professores do campo no Acre vem sendo muito desigual e, sistematicamente, muito baixa, se comparada a dos professores da cidade. Na cidade, 92,2 \% dos docentes possuíam nível superior, os que faziam parte do quadro efetivo, recebiam $\mathrm{R} \$ 2.010,95$, o que correspondia a três salários mínimos em $2013^{4}$. Já no campo, somente 65,2\% dos docentes possuíam ensino superior. Como dito anteriormente, existe uma diferença entre a remuneração dos professores efetivos e temporários. Estes, por sua vez, recebem, hoje, apenas 90\% da remuneração inicial de um efetivo, o que corresponde a $\mathrm{R} \$ 1.809,86$, uma diferença de $\mathrm{R} \$ 201,09$. Como no campo há mais professores temporários, essa é a realidade de muitos docentes.

Os professores com formação em nível médio magistério, do campo, recebiam o mesmo salário inicial dos professores efetivos, o que correspondia, em 2013, a R\$ $1.175,79$. No entanto, na cidade, somente $6,2 \%$ dos professores recebiam essa remuneração, ao passo que, no campo, a proporção era maior, 11,7\%. Os professores com ensino médio, sem habilitação no magistério, recebiam $\mathrm{R} \$ 754,00$. Na cidade, apenas 1,6\% dos professores recebiam esse valor; por outro lado, no campo, a proporção de docentes era maior, $14,2 \%$.

Os professores que possuíam formação no ensino fundamental recebiam $\mathrm{R} \$ 678,72$, o que correspondia ao valor do salário mínimo em 2013. No campo, 8,9\% dos docentes recebiam esse valor. Na cidade, essa realidade já não é encontrada, pois não existem mais professores com ensino fundamental.

Para reverter essa situação a saída é elevar a formação dessa parcela de professores que atuam no campo e são leigos, pois sendo leigos, seus salários não podem equivaler aos demais professores formados em nível superior. Mais crítica ainda é a situação dos professores temporários, que realizam o mesmo trabalho que os de nível superior e ganham $10 \%$ a menos. O Estado vem utilizando uma política de economia de recursos 
que precariza as condições de trabalho desses professores. Em virtude de, no campo, encontrarem-se mais professores temporários que na cidade, as desigualdades são grandes e aprofundadas, em relação às condições de trabalho do profissional.

Outro agravante que repercute diretamente nas condições de vida e de salário dos professores, é que, nas escolas do campo, especialmente as que possuem salas multisseriadas, o professor é o único profissional responsável pelas atividades na escola. Não existem outros profissionais que o auxiliem. Dessa forma, o professor assume outras funções, como faxineiro, diretor, secretário, merendeiro, entre outras, causando uma desvalorização do profissional, o que se expressa, principalmente, na remuneração.

$\mathrm{O}$ atendimento às populações que vivem no campo é um grande desafio para o Estado, pois os custos para a gestão pública são, comparativamente, mais elevados do que na cidade. Isso acaba gerando grandes desigualdades na distribuição dos professores mais qualificados, nos melhores salários, nas condições de trabalho, dentre outras. O Acre investe pouco nas escolas e na carreira do professor do campo. O discurso de que a educação nessas localidades é cara e a ausência de investimentos tornam o processo mais caro ainda, porque reiteram a precariedade do trabalho do professor, o que acaba comprometendo a qualidade de ensino para as crianças e os jovens do campo.

\section{Considerações Finais}

O perfil dos professores do Acre sinalizou que a valorização dos professores está consubstanciada na política de formação. Não restam dúvidas de que a formação é um elemento importantíssimo para a valorização. Os programas de formação vêm cumprindo o seu papel de elevar a titulação dos docentes, o que não deixa de ser uma tentativa de corrigir as históricas desigualdades sofridas pelos professores do campo, contudo estas vêm sendo planejadas e executadas de forma isolada e desarticuladas de outras categorias que são fundamentais para a valorização docente.

Por mais que os programas de formação, como o Profir, tenham contribuído para a redução dos professores leigos no campo, as desigualdades são visíveis quando se considera o vínculo profissional, a remuneração e as condições de trabalho entre os professores do campo e da cidade. A política de formação só será capaz de reduzir os efeitos das desigualdades e promover maior equidade quando for integrada à estruturação da carreira docente, à política salarial que assegure a dignidade do professor e à garantia de condições adequadas de trabalho no campo, pois, sem essas condições, as politicas de caráter emergencial acabam se tornando permanentes, na medida em que continuarão faltando professores qualificados no campo, porque o problema da valorização persiste.

No momento em que se implementa, no País, mais um Plano Nacional de Educação (PNE) para os próximos dez anos, e o primeiro Plano Estadual institucionalizado no Acre, 
faz-se necessário revisitar as proposições de formação e de valorização dos profissionais da educação, estabelecendo prioridades, com ações que tragam resultados reais para o trabalho docente. A formação e valorização precisam ser assumidas como compromisso dos governos no desenvolvimento de políticas públicas que viabilizem sua execução.

Recebido em janeiro de 2016 e aprovado em abril de 2016

\section{Notas}

1 São consideradas como horas de atividades aquelas destinadas à preparação e avaliação do trabalho didático, à colaboração com a administração da escola, às reuniões pedagógicas, à articulação com a comunidade e ao aperfeiçoamento profissional, de acordo com a proposta pedagógica de cada escola.

2 De acordo com a Conferência Nacional dos Trabalhadores em Educação (CNTE, 2010), o PSPN não é o salário total e nem a remuneração do profissional de educação, é o valor mínimo abaixo do qual não pode ser fixado o vencimento base ou salário base do professor em início de carreira.

3 Dentre eles, destacam-se o Programa Especial de Formação de Professores para a Educação Básica Pefpeb, com habilitação para a eeducação iinfantil e anos iniciais do eensino fundamental - llicenciatura plena em ppedagogia (2001) e o Programa Especial para atender os professores dos anos finais e ensino médio.

Em 2013, o valor do salario mínimo era de $\mathrm{R} \$ 678,00$.

\section{Referências}

ACRE. Lei Complementar nº 67, de 29 de junho de 1999. Dispõe sobre o Plano de Cargos, Carreira e Remuneração dos Profissionais do Ensino Público Estadual e dá outras providências. Assembleia Legislativa do Estado do Acre. Rio Branco, 1999. Disponível em: <http. www.aleac.ac.gov.br>. Acesso em: 03 fev.2014.

Governo do Estado. Lei nº 2.965, de 2015. Institui o Plano Estadual de Educação (PEE-AC). Rio Branco: SEE, 2015-2024.

BRASIL. Lei no 9.394, de 20 de dezembro de 1996. Institui a Lei de Diretrizes e Bases da Educação Nacional. Diário Oficial da União, Poder Executivo, Brasília, DF, 23 dez. 1996. Disponível em: <http:// www.planalto.gov.br/ccivil_03/leis/19394.htm>. Acesso em: 16 jun. 2013.

. CNE. Lei no 11.783, de 2008. Piso Salarial Profissional Nacional. Diário Oficial da União, Brasília, 2008. Disponível em: <http://planalto.gov.br/ccivil_03/_Ato2007-2010/2008/Lei/L11738.htm.> Acesso em: 15 jun. 2013.

. CNE; CEB. Resolução nº 2, de 2009. Fixa Diretrizes Nacionais para os Planos de Carreira e Remuneração dos Profissionais do Magistério da Educação Básica Pública, 2009. Diário Oficial da União, Poder Executivo, Brasília, DF, fevereiro 2009. Disponível em: <http://portal.mec.gov.br/ dmdocuments/resolucao_cne_ceb002_2009.pdf. > Acesso em: 17 jun. 2013. 
Lei no 13.005, de 25 de junho de 2014. Aprova o Plano Nacional de Educação e dá outras providências. Diário Oficial da União. Brasília, DF, 25 de junho de 2014. Disponível em: <http:// presrepublica.jusbrasil.com.br/legislacao/125099097/lei-13005-14>. Acesso: 26 jun.2014.

DAMASCENO, Ednaceli. Abreu. $\mathrm{O}$ trabalho docente no movimento de reformas educacionais no Estado do Acre. Tese (Doutorado em Educação). Universidade Federal de Minas Gerais, Belo Horizonte - MG, 2010.

GROCHOSKA, Marcia Andreia. Políticas Educacionais e a valorização do professor: carreira e qualidade de vida dos professores de educação básica do município de São José dos Pinhais/PR. Tese (Doutorado em Educação). Universidade Federal do Paraná, Curitiba - PR, 2015. 


\section{Teacher appreciation policies \\ The reality of teachers in rural areas}

ABSTRACT: The study aims to analyze the valuation policies for rural based teachers in the state of Acre, in order to show whether they are producing improved conditions to reduce the effects of inequality, and providing conditions for more equity in the educational setting, as the increase in obtaining qualifications for teachers has been planned and executed in an isolated and disjointed manner.

Keywords: Educational policies. Rural-based teachers. Teacher appreciation.

\section{Les politiques de valorisation des enseignants Une réalité des professeurs en milieu rural}

RÉSUMÉ: Ce travail se propose d'analyser les politiques de valorisation des enseignants du milieu rural de l'état de l' Acre, afin de montrer si celles-ci produisent de fait des conditions de valorisation qui réduiraient les effets de l'inégalité et permettraient des conditions plus équitables dans le scénarion éducatif, alors que l'augmentation des diplômés est planifiée et concretisée de manière isolée et desarticulée.

Mots-clés: Politiques éducatives. Professeurs en milieu rural. Valorisation des enseignants.

\section{Las políticas de valoración docente Una realidad de los profesores del campo}

RESUMEN: El trabajo propone un análisis de las políticas de valoración de los profesores del campo en el estado de Acre, con el fin de comprobar si estas están produciendo condiciones de valoración para reducir los efectos de la desigualdad y propiciando condiciones más igualitarias en el escenario educativo, ya que el aumento en la titulación se viene planificando y ejecutando de manera aislada y desarticulada.

Palabras clave: Políticas educativas. Profesores del campo. Valoración docente. 